\title{
DE VERWERKING VAN PRIJSFLUCTUATIES IN DE JAARREKENING
}

\author{
door Drs. I. Kleerekoper
}

\section{Inleiding}

Een internationale vergelijking van de regelgeving op het gebied van de ver. werking van prijsfluctuaties in de jaarrekening dwingt, gezien de complexiteit van de te regelen problematiek en de op een niet onbelangrijk aantal punten divergerende aanpak en/of uitwerking daarvan, tot het aanbrengen van een drastische beperking in het aantal te bespreken, zich nog in een ontwerp-stadium dan wel in definitieve vorm bevindende, voorschriften. Zulk een beper. king biedt dan wel de mogelijkheid de te bespreken voorschriften in een voor de vergelijking noodzakelijk geachte detaillering weer te geven; de details zijn noodzakelijk omdat slechts daardoor voldoende inzicht geboden wordt in de richting waarin en de wijze waarop het aan de orde zijnde vraagstuk door de regelgevende instantie tot oplossing, dan wel tenminste een stap verder, ge. bracht is.

Besproken worden achtereenvolgens:

- de Internationale Standaard IAS 6 en vooral E 17;

- de Britse SSAP 16;

- de Amerikaanse FAS 33;

- de Nederlandse Richtlijnen TO en de ontwerp-aanpassing Vierde Europe. se Richtlijn.

Zonder tekort te doen aan wat elders ter wereld te dezer zake tot stand ge. bracht is, kan toch wel worden gesteld dat - zeker vanuit de Nederlandse op. tiek - met de vermelde publikaties het belangrijkste materiaal op regelgevend gebied ter tafel komt. Op de voorgeschiedenis van met name SSAP 16 en FAS $33 \mathrm{zal}$ niet worden ingegaan, niet omdat die voorgeschiedenis niet interessant zou zijn, integendeel, maar uitsluitend om der ruimte wille.

Het artikel wordt afgesloten met een summiere vergelijkende nabeschou. wing.

\section{Internationale Standaard IAS 6 en E 17}

Het International Accounting Standards Committee (IASC) verkeert ter zake van zich nog in jeugdige groei - somtijds zelfs wildgroei - bevindende vraagstuk. ken als het onderhavige in de moeilijke positie dat van een eerst inventarise. rende, dan toetsende en tenslotte harmoniserende functie, zoals die ter zake van menig ander onderwerp vervuld wordt, geen sprake kan zijn. In plaats van het vraagstuk van ,inflation accounting”, of beter geformuleerd van „accoun. ting for the effects of changing prices", dan maar te laten rusten, is gekozen voor een de internationale kring stimulerende benadering. Op 1 maart 1977 
mondde die benadering uit in de publikatie van een „discussion paper” getiteld "Treatment of changing prices in financial statements; a summary of proposals", gevolgd in juni 1977 door de standaard IAS 6 met als onderwerp „Verwerking van prijsfluctuaties".

Deze standaard bevatte de uitspraak, dat bedrijfshuishoudingen in hun jaar rekening informatie dienen te geven over de methode, toegepast om het effect van prijsfluctuaties - hetzij specifieke, hetzij algemene, dan wel beide - op die jaarrekening weer te geven. Zijn zodanige methoden in het geheel niet toegepast, dan dient van dit feit melding gemaakt te worden.

Of, en zo ja, in welke mate van IAS 6 de beoogde stimulerende werking is uitgegaan, valt moeilijk vast te stellen; vast staat slechts dat sinds 1977 heel wat gezwoegd is aan, maar toch ook heel wat tot stand gebracht is op het gebied van de regelgeving omtrent de invloed van prijswijzigingen op de financiële verslaglegging. Te noemen vallen in dit verband de elkaar opvolgende, zij het niet steeds harmonisch op elkaar aansluitende, ontwerpen en standaarden in het Verenigd Koninkrijk, in de Verenigde Staten, maar ook in Australië, Ca. nada en Zuid-Afrika, terwijl ook de tot stand gekomen Vierde Europese Richt. lijn en zijn nasleep vermeld dienen te worden. In die ontwikkelingen zag het IASC aanleiding een stap(je) verder te zetten op het pad der stimulering; op 1 augustus 1980 zag dientengevolge het Ontwerp ter Discussie E 17 ,Informa. tie waaruit de invloed van prijsfluctuaties blijkt" het licht.

Het is - zo wordt daarin gezegd - nog te vroeg om reeds de verwerking van zodanige informatie in de primaire jaarstukken, onder toepassing van een het geheel omvattende en uniforme methode, te eisen; waar de jaarrekening op basis van historische kostprijzen wordt opgesteld kan daarom met aanvullende informatie omtrent de gevolgen van prijsfluctuaties worden volstaan; het is ge. wenst een internationaal minimum voor die aanvullende informatie vast te stellen.

Dit minimum, neergelegd in E 17:

- berust op de grondslag van „een methode die leidt tot correctie van het effect van prijsfluctuaties"; met deze formulering wordt ruimte gelaten aan zowel actuele waarde als algemene koopkrachtmethoden, alsook aan een combinatie van beide (nochtans ademt de "Toelichting" een duidelijke voorkeur voor toepassing van actuele waarde);

- omvat in elk geval (dus eigenlijk als minimum) de correctie of het gecor. rigeerd bedrag van de afschrijving op vaste activa en van de kostprijs van de omzet;

- omvat voorts ,indien dit in het algemeen behoort tot de toegepaste me thode voor het verschaffen van informatie aangaande prijsfluctuaties" één of meer financieringscorrecties; deze formulering impliceert de vrijheid om géén financieringscorrectie toe te passen; is er wèl behoefte aan zulk een correctie, dan dient deze te passen in de gekozen „methode”; dit voor. onderstelt zodoende consistentie; in de "toelichting" wordt de financie. ringscorrectie uitsluitend aan de actuele-waarde-methode gekoppeld en worden als correcties genoemd:

a. correctie op het saldo der geldposten (net monetary items; zie FAS 33);

$b$. correctie op middelen benodigd voor instandhouding van het werkka pitaal (monetary working capital; zie SSAP 16); 
c. de overbrengingscorrectie (een wat moeizame maar letterlijke vertaling van ,gearing adjustment"; zie SSAP 16);

d. correctie door middel van toepassing van een algemene prijsindex op het eigen vermogen (deze laatste correctie is van Nederlandse zijde als mogelijkheid ingebracht en althans in de ontwerp-standaard opgenomen);

- omvat het herrekende resultaat met inachtneming van vorengenoemde elementen, ,,alsmede eventuele andere afzonderlijk weergegeven posten, waarvoor de gekozen methode dit vereist"; ook hier wordt weer ruimte gelaten voor vrijheid, in casu vrijheid voor een nadere definiëring van de in. houd van het begrip „resultaat” (hetgeen tegen de achtergrond van de Brit. se en Amerikaanse standaarden - zie aldaar - wel nodig is), alsook vrijheid om méér informatie te verschaffen, zoals bijvoorbeeld omtrent het belas. tingeffect; zulke meerdere informatie dient dan wel in de herrekening van het resultaat te worden meegenomen;

- omvat tenslotte een beschrijving van de toegepaste werkwijze bij het be rekenen van de samenstellende delen van het herrekende resultaat, waar. bij de aard van eventueel gebruikte index cijfers dient te worden vermeld. Alles bijeengenomen is hier sprake van een concept-standaard welke beoogt te bewerkstelligen dat tenminste informatie over het effect van prijsfluctuaties op afschrijvingen en op de kostprijs van de omzet wordt verschaft en daaren. boven tracht te bevorderen dat mééromvattende methoden tot ontwikkeling komen.

\section{Verenigd Koninkrijk: \\ Statement of Standard Accounting Practice No 16 (SSAP 16)}

Deze van maart 1980 daterende Britse standaard, getiteld „Current Cost AC. counting” heeft als uitgangspunt, dat de „net operating assets” - bestaande uit vaste activa, voorraden en "monetary working capital” - te zamen de „operating capability" van de bedrijfshuishouding vormen. Volgtijdelijke prijswijzigin. gen beinvloeden de omvang van de middelen die nodig zijn voor het in stand houden van de „operating capability”. Slechts „current cost accounts” zijn - in tegenstelling tot "historical cost accounts” - in staat die invloed bij de winst-en vermogensbepaling tot uitdrukking te brengen.

Dit uitgangspunt heeft tot consequentie, dat de standaard voorschrijft dat „annual financial statements of entities coming within the scope of the Standard should include, in addition to historical cost accounts or historical cost infor. mation, current cost accounts prepared in accordance with this Standard".

Het vorenstaande houdt in, dat de publicerende huishouding mag kiezen, welke opstelling - die op basis van ,current cost” dan wel die op basis van „historical cost" - zij als haar primaire verantwoording wenst te presenteren en welke opstelling zodoende als aanvullend dient te worden aangemerkt. Merk. waardigerwijs kan ze echter ook voor "current cost accounts” als enige verant. woording kiezen (een keuze welke voor de opstelling op historische kosten ba sis niet is toegestaan), in welk geval geen „full historical cost accounts" behoe. ven te worden gegeven, doch met ,,adequate historical cost information" kan 
worden volstaan. Voor laatstgenoemde informatie wordt verwezen naar de komende aanpassingswetgeving aan de Vierde Europese Richtlijn. Met de geboden alternatieven heeft men klaarblijkelijk de weg willen openlaten naar een ontwikkeling in de richting van het kiezen van "current cost accounts” als primaire of zelfs enige verantwoording; nochtans ademt de verdere uitwerking de geest van een - stellig realistische - veronderstelling dat er primaire jaarstukken zullen zijn op basis van historische kosten en dat die vergezeld zul len gaan van de voorgeschreven „current cost accounts” bestaande uit een winst- en verliesrekening, een balans en de daarbijbehorende toelichting.

De paragrafen gewijd aan de winst- en verliesrekening gaan dan ook uit van de op basis van de historische kosten berekende bedrijfswinst en schrijven vervolgens een aantal ,adjustments" voor om tot de na te noemen ,current cost operating profit" en „current cost profit attributable to shareholders" te geraken. De vaststelling van de perioderesultaten dient namelijk te geschieden in twee fasen. De eerste fase omvat dan het resultaat van de normale bedrijfs. activiteiten van de huishouding, na het in aanmerking nemen van de invloed van prijswijzigingen op de middelen nodig voor voortzetting van die activiteiten onder instandhouding van de „operating capability”, doch zonder nog re. kening te houden met de wijze waarop één en ander is gefinancierd; interest en belastingen worden in deze fase dan ook niet in aanmerking genomen; deze eerste fase wordt aangeduid als de vaststelling van de „current cost operating profit". In de tweede fase wordt de invloed van de financiering tot uitdrukking gebracht en wel zodanig, dat voorzover de aan prijswijziging onderhevige „net operating assets" met vreemd vermogen (,,borrowing") gefinancierd blijken te zijn, de in de eerste fase uit hoofde van die prijswijzigingen opzij gezette mid. delen voor een overeenkomstig deel door middel van een "gearing adjustment" weer teruggenomen worden; dat deel dier middelen is immers niet nodig, nu de geldgevers daarop geen aanspraak kunnen maken; wat overblijft is dan het bedrag aan middelen dat nodig is om de portie van aandeelhouders in de "operating capability” van de huishouding in stand te houden. De „current cost profit attributable to shareholders" wordt voorts getoond na het in aanmerking nemen van interest, belastingen en buitengewone baten en las. ten.

Naast de vorengenoemde twee-fasen winst en verliesrekening omvat de voorgeschreven presentatie een balans, waarin de activa worden opgenomen voor hun „value to the business based on current price levels", hetgeen een realistische vergelijking mogelijk maakt tussen winst en eigen vermogen op ac. tuele waarde basis.

Tot zover de weergave van de achtergronden van SSAP 16, ontleend aan de daarin opgenomen toelichting. Bij de verdere uitwerking blijkt het begrip "value to the business" zulk een belangrijke rol te spelen, dat bij de betekenis daarvan hier even stil gestaan moet worden. Onder deze "bedrijfswaarde” wordt verstaan de (actuele) vervangingswaarde (,net current replacement cost") dan wel, bij onderkenning van een permanente waardedaling beneden dat niveau, de opbrengstwaarde, welke op haar beurt weer is de hoogste van directe of indirecte opbrengstwaarde. 
De winstberekening, uitgaande van het bedrijfsresultaat op historische kosten basis, verloopt nu stap voor stap als volgt:

- startpunt

historisch bedrijfsresultaat, vóór interest en belastin. gen;

- correctie no. 1 : op afschrijvingen vaste activa, het verschil tussen de bedrijfswaarde en de historische kostprijs van de ver. bruikte capaciteit;

- correctie no. 2 : op kostprijs verkopen, het verschil tussen de bedrijfs. waarde en de historische kostprijs van de verbruikte voorraden;

- correctie no. 3 : op „monetary working capital”, een verhoudingsge wijs even grote correctie als die onder no. 2, doch thans berekend over het werkkapitaal, voorzover be. staande uit geldposten, meestentijds slechts omvat. tend debiteuren minus crediteuren (opdat de invloed van prijswijzigingen tot uitdrukking gebracht wordt over het gehele werkkapitaal en niet alleen over het voorraadbestanddeel daarvan);

- tussenresultaat : bedrijfswinst op actuele waarde basis (current cost operating profit);

- correctie no. 4 : de "gearing adjustment", zijnde het van het totaal der correcties $1 \mathrm{t} / \mathrm{m} 3$ terug te nemen deel, overeenkomend met de verhouding waarin het niet tot het werkkapitaal behorend netto vreemd vermogen (net borrowing) staat tot het netto bedrijfsgebonden actief (net operating assets);

- interest op het netto langlopend vreemd vermogen;

- belastingen;

- buitengewone baten en lasten;

- eindresultaat; aan aandeelhouders toe te rekenen resultaat op actuele waarde basis.

Wat de bijpassende balans betreft: naast een volledige balans op basis van his torische kostprijzen mag met een samengetrokken exemplaar op actuele waar. de grondslag worden volstaan; de vaste activa en voorraden dienen daarin op bedrijfswaarde in vorenomschreven zin gewaardeerd te worden; de bedragen uit herwaardering van activa en uit de vier in het kader van de winstbereke ning behandelde „adjustments” dienen in een „current cost reserve” verant woord te worden. In de toelichting dient getoond te worden het totaalbedrag van de "net operating assets” en van "net borrowing”, alsmede hun belang. rijkste componenten.

Bij het hiervoren uiteengezette inzake de winst- en vermogensbepaling in de „current cost accounts” passen nog de navolgende kanttekeningen:

- de bedrijfswaarde wordt gevormd door de vervangingswaarde of de lage re opbrengstwaarde, waarbij als criterium voor overgang naar de op brengstwaarde wordt gegeven de onderkenning van een permanente waardedaling onder het vervangingswaardeniveau; blijkens de definitie 
geldt dit criterium zowel voor vaste activa als voorraden; van een continuiteitscriterium is hier zodoende geen sprake;

- meestentijds omvat het "monetary working capital" slechts debiteuren en crediteuren, hetgeen impliceert dat de aan te brengen correctie uit dezen hoofde, afhankelijk van de omvang van elk dier beide posten, ook negatief kan uitvallen;

- soms kan het geboden zijn ook liquide middelen c.q. bankschulden in het „monetary working capital” op te nemen, namelijk voor zover fluctuaties in de omvang van voorraden, debiteuren en crediteuren zulks ter egalisatie nodig doen zijn; een uiterst vage suggestie die tot willekeur kan leiden;

- het is toegestaan de voorraden en het „m.w.c.” samen te voegen en als één geheel te presenteren en te corrigeren, onder de aanduiding ,working capital";

- in het kader van de "gearing adjustment" is vastgelegd, dat de tot uitgangs. punt te nemen financieringsverhouding een retrospectieve grootheid is en zodoende bepaald dient te worden op basis van de werkelijke situatie in de verslagperiode; het ,nemen" van de financieringswinst is niet afhanke. lijk van de verwachting inzake de mogelijkheid ener adequate herfinanciering;

- onder erkenning van verschillende opvattingen ter zake, wordt de voor. geschreven wijze van berekening van de "gearing adjustment" als beste ge handhaafd; afwijkende opvattingen c.q. berekeningen mogen in de toe lichting worden opgenomen;

- de instandhoudingsdoelstelling is duidelijk: het gaat om het in stand houden van de produktieve capaciteit in twee fasen, in de eerste fase in totaal en in de tweede fase alleen voor de portie van aandeelhouders;

- de Standaard geeft grondregels, maar wenst niet de methoden waarmee tot c.c.a. gekomen wordt voor te schrijven; men beperkt zich tot "guidance notes"; vandaar dat de Standaard voorschrijft dat in de toelichting een uiteenzetting van de de facto gehanteerde methoden wordt gegeven;

- de ter beurze genoteerde vennootschappen dienen de winst per aandeel op basis van „current cost profit attributable to shareholders” vóór buitengewone posten te tonen;

- worden geconsolideerde jaarstukken op actuele waarde basis gegeven, dan behoeft dat niet voor de juridische jaarrekening van de moedervennoot. schap.

\section{Verenigde Staten:}

Statement of Financial Accounting Standards No 33

Onder de titel „Financial Reporting and Changing Prices" werd in september 1979 in de Verenigde Staten de in hoofde genoemde „statement” gepubliceerd door de F.A.S.B. (Financial Accounting Standards Board). Als uitgangspunt wordt genomen de constatering dat „velen geloven” dat gebruikers van jaarrekeningen behoefte hebben aan kwantitatieve voorstellingen (measurements) uitgedrukt in eenheden van constante koopkracht (general purchasing power), terwijl ook „,velen geloven” dat jaarrekeningen op basis van historische kosten tekort schieten nu zij de gevolgen van specifieke prijswijzigingen niet 
tot uitdrukking brengen. Vandaar dat de standaard voorschrijft om, naast de primaire jaarcijfers op basis van historische kosten, aanvullende informatie te verschaffen in eenheden van constante koopkracht en tevens informatie welke gebaseerd is op de „current cost” van voorraden en vaste activa. De praktijk zal - zo hoopt men - uitwijzen welke informatie het grootste nut afwerpt en via het experimenteren binnen de verstrekte richtlijnen - welke methoden en technieken om tot die informatie te geraken het best aan hun doel beantwoor. den.

De in de standaard voorgeschreven aanvullende informatie dient te omvatten:

a. ,income from continuing operations" - zijnde het bedrijfsresultaat na be. lastingen, doch met uitsluiting van de uitkomsten van beëindigde activiteiten, buitengewone posten en de cumulatieve invloed van systeemwijzigin gen - op basis van historische kosten, doch uitgedrukt in eenheden van constante koopkracht, alsmede vermelding van de - overigens niet in de bedrijfswinst te verwerken - inflatiewinst of -verlies op het netto monetaire actief;

b. „income from continuing operations" op actuele waarde basis, alsmede de vermelding van de actuele waarde van voorraden en vaste activa per ba lansdatum en van hun toe- of afname gedurende de verslagperiode, „net of inflation"; laatstgenoemde toe of afname dient buiten de bedrijfswinst te blijven;

c. een 5-jaars overzicht van bepaalde gegevens, zoals: de omzet; het bedrijfsresultaat in totaal en per gewoon aandeel, alsmede het netto actief, dit alles berekend zowel op basis van a. als b.; het dividend en de koerswaarde per gewoon aandeel; bij al deze gegevens vermeldend de voor elk dier 5 jaren geldende hoogte van de gehanteerde algemene prijsindex.

Ter zake van de uitwerking van de hiervoren genoemde aanvullende informatie volgen hieronder voor elk der drie categorieën nog enkele daarbij van be. lang zijnde punten.

ad a. Informatie op basis van constante koopkracht:

- men gebruike hiervoor het indexcijfer van de kosten van levensonderhoud (Consumer Price Index);

- vereist is het toepassen van koopkrachtcorrecties op voorraden, vaste ac. tiva, kostprijs-verkopen en afschrijvingen, alsmede op de eventuele aanpassing in neerwaartse richting van historische kostprijs naar lagere op. brengstwaarde;

- de koopkrachtcorrectie vindt plaats naar de gemiddelde stand van de in. dexcijfers in de verslagperiode.

ad b. Informatie op basis van actuele waarde:

- voorraden zowel als (de resterende capaciteit van) vaste activa worden gewaardeerd op hun vervangingswaarde of lagere opbrengstwaarde op het waarderingstijdstip;

- kostprijs-verkopen wordt gewaardeerd op vervangingswaarde of lagere opbrengstwaarde op het tijdstip van verkoop;

- afschrijvingen worden gewaardeerd op de gemiddelde vervangingswaar.

ma blz. 276 
de of lagere opbrengstwaarde van de desbetreffende activa gedurende de verslagperiode;

- het bedrag van de belastingpost ten laste van de bedrijfswinst op actuele waarde-basis dient gelijk te zijn aan het bedrag dat ten laste van de resul. tatenrekening op basis van historische kosten blijkt te zijn gebracht; het is zodoende niet toegestaan de invloed van de gewijzigde waardering op de belastingpost tot uitdrukking te brengen;

- de toe of afname van de actuele waarde van voorraden en vaste activa (sedert de vorige balansdatum danwel latere verwerving en tot de huidige balansdatum danwel eerdere verkoop of verbruik) dient weergegeven te worden zowel vóór als nà toepassing van een algemene koopkrachtcorrec. tie daarop;

- bij de vaststelling van vervangingswaarden is zowel het gebruik van (exter. ne en interne) indexcijfers als van specifieke prijzen toegestaan;

- de opbrengstwaarde mag alleen worden toegepast, indien zij "materially and permanently" lager geacht wordt te zijn dan de vervangingswaarde (c.q. de historische kostprijs in constante koopkracht), waarbij eer naar groepen activa dan naar individuele activa wordt gekeken.

\section{ad c. Het vijf-jaars overzicht:}

de hierin opgenomen gegevens dienen te worden uitgedrukt in eenheden van constante koopkracht, hetgeen impliceert dat de cijferreeksen van elk afzonderlijk jaar, telkenmale dat ze weer in een volgend vijfjarenoverzicht verschijnen, dienen te worden geïndexeerd om te worden gebracht op de koopkracht van het jongste verslagjaar.

In een bijlage bij de standaard worden bij wijze van illustratie twee verschil lende opstellingen gegeven voor de hiervoren sub a. en b. genoemde aanvul. lende informatie. Het eerste voorbeeld is een verticale opstelling, welke begint met het bedrijfsresultaat - zoals eerder gedefinieerd - ontleend aan de officiële winst - en verliesrekening en zodoende op basis van historische kosten; daarop worden nu eerst correcties voor kostprijs-verkopen en afschrijvingen toegepast, nodig om te komen tot het bedrijfsresultaat ,adjusted for general infla. tion"; vérvolgens worden andermaal correcties voor kostprijs-verkopen en af. schrijvingen toegepast, doch thans voor het verschil tussen de invloed van ,ge. neral inflation and changes in specific prices (current costs)", waarmee gekomen wordt tot het bedrijfsresultaat op actuele-waarde-basis. Het andere voorbeeld geeft naast elkaar drie opstellingen, elkéén uitmondend in de bedrijfs. winst, achtereenvolgens naar historische kosten zonder meer, naar historische kosten herrekend in eenheden van constante koopkracht en tenslotte naar ac. tuele waarde.

In beide voorbeelden volgen dan nog als afzonderlijke grootheden: inflatie winst of -verlies op het netto monetair actief; de toename van de actuele waar. de van voorraden en vaste activa gedurende het jaar, gesteld naast de toename zoals die op basis van de algemene koopkracht ontwikkeling geweest zou zijn, uitmondend in het verschil tussen beide grootheden. 


\section{Nederland:}

\section{richtlijnen T.O. en Ontwerp Aanpassing Vierde Europese Richtlijn}

De Wet op de Jaarrekening van Ondernemingen (thans BW boek 2 Titel 6) bevat ter zake van de in de jaarrekening toepasbare waarderingsgrondslagen slechts de zeer algemene bepaling, dat deze dienen te voldoen ,aan normen die in het maatschappelijk verkeer als aanvaardbaar worden beschouwd". Het ter inventarisering dier normen in het leven geroepen Tripartiete Overleg heeft in zijn ,Richtlijnen voor de Jaarrekening” (Ontwerp juni 1980) in hoofd stuk 1.03, getiteld „Prijsgrondslagen”, uitgesproken dat in de jaarrekening met betrekking tot vaste activa en voorraden zowel op basis van actuele waarde als op basis van historische prijzen informatie over vermogen en resultaat verschaft dient te worden. Het laat daarbij in het midden, welke basis voor de pri. maire informatie wordt gekozen en welke voor de aanvullende informatie; ge. eist wordt echter wel stelselmatigheid, zowel gelijk - als volgtijdelijk; deze eis im pliceert dat voor balanswaardering en resultaatbepaling eenzelfde waarderingsgrondslag (historische prijzen danwel actuele waarde) wordt gehanteerd.

Onder actuele waarde wordt normaliter verstaan de vervangingswaarde; pas indien bij discontinuïteit van activiteiten vervanging van vaste activa en/of voorraden niet meer in het voornemen ligt, zal de opbrengstwaarde bepalend zijn. Voor voorraden geldt evenwel de daaroverheen grijpende regel dat waardering op netto-opbrengstwaarde steeds geboden is, indien deze lager is dan de op historische prijzen of vervangingswaarde gebaseerde boekwaarde. Uitdrukkelijk wordt in dit verband nog vastgelegd, dat verliesgevendheid op zichzelf geen grond oplevert tot het prijsgeven van de vervangingswaardegrondslag; integendeel wordt benadrukt dat bij voortzetting van de activiteiten voor onbepaalde tijd het tot uitdrukking brengen van de daarmede gemoeide verliezen slechts bij handhaving van die grondslag op juiste wijze kan geschieden. Pas na een beslissing tot beëindiging van een activiteit kan tot afwaardering worden overgegaan; beëindiging op korte termijn brengt de vaste activa op hun directe opbrengstwaarde; beëindiging op langere termijn leidt tot afwaar. dering op indirecte opbrengstwaarde.

De nadere uitwerking in de hoofdstukken 2.02 voor „Vaste activa en afschrij vingen” en 2.06 voor "Voorraden en kosten van het goederenverbruik” doet zien dat:

- de vervangingswaarde primair dient te worden bepaald op basis van specifieke prijsgegevens en pas in de laatste plaats op basis van indexcijfers van branche-organisaties of statistische bureaus;

- dat bij vaste activa in geval van niet identieke vervanging de prijsontwik. keling zoveel mogelijk dient te worden geschoond voor de effecten van technologische ontwikkelingen;

- dat de actuele waarde van de opgeofferde voorraden benaderd kan wor. den met behulp van het lifo-stelsel of het ijzeren voorraadstelsel; voor de balanswaardering der voorraden zijn deze stelsels echter niet aanvaard. baar, zodat alsdan een andere methode voor het bepalen van hun actuele waarde gevolgd moet worden.

Intussen zijn niet onbelangrijke wijzigingen in wet- en regelgeving te verwach- 
ten ten gevolge van de aanpassing van het BW aan de Vierde Europese Richtlijn betreffende de jaarrekening. Deze Richtlijn is tot stand gekomen op 25 juli 1978 en bevat, voorzover in het onderhavige verband van belang, weliswaar het algemene voorschrift van waardering van de posten in de jaarrekening op basis van het beginsel van de aanschaffings of vervaardigingskosten (art. 32), doch laat vervolgens (art. 33 lid 1) ruimte voor de lid staten om toe te staan, of zelfs voor te schrijven, dat

a) vaste activa en voorraden worden gewaardeerd op basis van de vervan. gingswaarde,

b) de posten in de jaarrekening, met inbegrip van het eigen vermogen, wor den gewaardeerd volgens andere methoden ten einde rekening te houden met inflatie en

c) vaste activa worden geherwaardeerd.

Een Ontwerp van Wet tot aanpassing van ons BW aan de Vierde Richtlijn is inmiddels bij de Tweede Kamer ingediend. Aan ontwerp en toelichting daarop valt te ontlenen:

- waardering en winstbepaling mogen geschieden op basis van historische kosten danwel actuele waarde;

- de keuzevrijheid is echter niet onbeperkt; in geval de boekwaarde van een actief ,in een niet te verwaarlozen mate lager is dan de actuele waarde" dient in de toelichting aanvullende informatie te worden verschaft; zou on. danks die aanvullende informatie het inzicht dat de jaarrekening behoort te geven ,in ernstige mate worden geschaad", dan ontstaat de verplichting tot herwaardering tegen actuele waarde; waar de grens ligt tussen de beide voornoemde, in elkaar overlopende, gebieden is in het algemeen niet aan te geven; de concrete beslissing berust bij de bedrijfsleiding; de accountant toetst die beslissing op aanvaardbaarheid;

- overigens is er steeds de bevoegdheid tot herwaardering van vaste activa en voorraden tegen actuele waarden;

- inhoud, grenzen en wijze van toepassing van herwaardering tegen actuele waarde kunnen bij Algemene Maatregel van Bestuur nader worden gere. geld; het is kennelijk niet de bedoeling de toepassing van de in art. 33 lid l sub b) van de Vierde Richtlijn bedoelde algemene-koopkracht-methode mogelijk te maken; van deze methode wordt gesteld dat daarbij niet van een methode van waardering van activa en passiva sprake is;

- slechts wegens gegronde redenen mag van de in de voorafgaande jaarre kening gehanteerde grondslagen worden afgeweken, zulks onder vermelding van die redenen en van de invloed op vermogen en resultaat;

- het verschil tussen de boekwaarde van een actief vóór en na een plaats. gevonden herwaardering moet op de balans in een herwaarderingsreserve tot uitdrukking komen; de herwaarderingsreserve moet als afzonderlij. ke post op de balans paraisseren; zij moet worden gesplitst naar de aard der activa waarop de herwaardering is toegepast;

- de herwaarderingsreserve kan in kapitaal worden omgezet; het is de be. doeling uit te sluiten dat opwaardering als winst wordt beschouwd of aan de vrije reserves wordt toegevoegd;

- de herwaarderingsreserve dient verminderd te worden voorzover zij niet 
meer noodzakelijk is voor de toepassing van het gekozen waarderingsstel. sel (b.v. bij overgang van waardering op actuele waarde naar waardering op historische prijzen) en evenmin voor het bereiken van het doel der her. waardering (b.v. wanneer het bedrijfsonderdeel waarin het betrokken ac. tief wordt gebruikt voorgoed wordt afgestoten); de vermindering van de herwaarderingsreserve mag slechts worden uitgekeerd of tot de winst wor. den gerekend, voorzover zij reeds als kosten-verkopen of afschrijvingen ten laste van de winst en verliesrekening blijkt te zijn gebracht, dan wel via vervreemding inmiddels is gerealiseerd;

- in de toelichting moet worden aangegeven of, en zo ja, hoe de herwaardering fiscaal wordt verwerkt; van enig voorschrift terzake van die verwer. king is geen sprake; hoewel de bewoording van art. 390 lid 1 (, ... neemt op de balans een herwaarderingsreserve op ter grootte van het verschil tussen de boekwaarde van vóór en na de herwaardering") lijkt te implice. ren dat het vormen van een belastingvoorziening ten laste van de herwaarderingsreserve niet zou zijn toegestaan, volgt uit de desbetreffende passages in de Memorie van Toelichting het tegendeel; aldaar wordt die mo gelijkheid, naast andere, uitdrukkelijk genoemd.

Het lijkt goed hier nog eens de aandacht te vestigen op de omstandigheid dat het ten tijde van het schrijven van het onderhavige artikel - zowel voor wat betreft de hiervoren besproken Richtlijnen van het Tripartiete Overleg als de Aanpassingswetgeving Vierde Richtlijn - om nog niet definitief vaststaande re. gelen gaat. Afgewacht dient te worden hoe de definitieve vorm van Richtlij. nen en Wet er zullen uitzien; het ligt echter in de lijn der verwachtingen dat van fundamentele wijzigingen daarin nauwelijks sprake zal zijn.

\section{Nabeschouwing}

Naar uit de voorgaande weergaven duidelijk blijkt, is er met betrekking tot de besproken stelsels naast menig punt van overeenkomst toch stellig sprake van een groot aantal verschilpunten. Het zou te ver voeren al die punten te reca. pituleren en naast elkaar te zetten; slechts een enkel saillant punt wordt hierna nog afzonderlijk aangestipt.

Uitsluitend in de V.S. is men ter zake van de verwerking van prijsfluctuaties in de jaarrekening niet tot een keuze kunnen komen tussen het verstrekken van (aanvullende) informatie op basis van actuele waarde enerzijds en de her rekening van de historische kostencijfers naar eenheden van constante koopkracht anderzijds. Weliswaar laat het IASC de keuze tussen de beide voomoem. de methoden - zij het schoorvoetend - open (om daarmee vooralsnog de V.S. te accommoderen), maar het zijn alleen de V.S. die in FAS 33 drie cijferreeksen naast of onder elkaar, n.l. primaire cijfers in historische prijzen, aanvullende cijfers in historische prijzen uitgedrukt in constante koopkracht en aanvullende cijfers in actuele prijzen, voorschrijven. In de besproken Britse en Nederlandse publikaties komt informatie op basis van eenheden van constante koopkracht niet (meer) ter sprake; gekozen wordt voor de toepassing van uitsluitend actue. le waarde naast de historische cijfers.

De Britten laten vervolgens de mogelijkheid van primaire cijfers op basis van actuele waarde en aanvullende informatie op basis van historische prijzen 
open, maar de gehele verdere uitwerking van SSAP 16 stoelt op historische kosten cijfers als startpunt voor de voorgeschreven herrekening van zowel re. sultaat als vermogen op actuele waarde grondslag. In Nederland laat het TO geen voorkeur blijken voor één van beide grondslagen voor wat betreft primaire of aanvullende informatie; hoofdzaak is, dat zowel informatie op actuele als op historische prijsgrondslag wordt verstrekt. Het Ontwerp-aanpassing BW tast de door het TO voorgestane vrije keuze echter danig aan; in een bepaalde situatie ontstaat daarin namelijk de verplichting tot herwaardering, welke ver. plichting alsdan tot één enkel activum beperkt kan zijn. Bij alle diversiteit, zoals deze uit de schildering van de internationale situatie oprijst en onder erken ning van het feit dat met die diversiteit vooralsnog geleefd zal moeten worden, moet toch het voorschrift tot een (vaak partiële) herwaardering, conform art. 384 lid 5 van het Ontwerp van Wet tot aanpassing BW aan Vierde Richtlijn, als een betreurenswaardige, geheel uit de pas van de internationale ontwik. keling lopende, noviteit gezien worden. Te hopen valt daarom dat men er in moge slagen deze bepaling bij de parlementaire behandeling uit het wetsont werp te elimineren.

Vervolgens kan worden vastgesteld dat alleen SSAP 16 een volledige herrekende resultatenrekening - zij het in twee etappes - tot en met het netto eind. resultaat expliciet voorschrijft. FAS 33 beperkt de herrekening tot het bedrijfs. resultaat, hetwelk per se niet tot de „bottom line” van de winst- en verliesre. kening bedoelt te reiken. Het IASC laat bewust een nadere definiëring van het te herrekenen resultaat in het midden. Het TO zegt, dat inzicht gegeven moet worden in omvang en samenstelling van het resultaat op basis van actuele waarden, maar de Ontwerp aampassingswet spreekt al naar de omstandigheden van aanvullende informatie, van de bevoegdheid tot herwaardering en van de verplichting tot herwaardering, zonder overigens het tonen van het re. sultaat op basis van actuele waarden voor te schrijven. De verwachting lijkt gerechtvaardigd dat ook na het tot stand komen van de Aanpassingswet de op vattingen van het $\mathrm{TO}$ te dezer zake richtinggevend blijven.

Het bijzondere van SSAP 16 is ongetwijfeld vooral, het naast de correctie op afschrijvingen en op de kostprijs van de omzet voorschrijven van een "monetary working capital adjustment" en vervolgens van een "gearing adjustment”. FAS 33 vereist wel de berekening van inflatiewinst of -verlies op „net monetary items”, doch alleen in het kader van „constant dollar" informatie, maar zonder verwerking in het resultaat. Het IASC laat alle financieringscorrecties toe. In de Nederlandse bronnen vindt men die echter niet.

De beide in SSAP 16 toegepaste correcties vormen een zowel nationaal als internationaal omstreden zaak. Het wordt geenszins algemeen als een logische stap beschouwd om volgtijdelijke waardeverschillen betrekking hebbend op materiële activa zonder meer te transplanteren naar de geldposten van het werkkapitaal en nog minder om de financieringsverhoudingen te hanteren als maatstaf voor het al dan niet tot de winst rekenen van die volgtijdelijke waardeverschillen. Het is daarom een goede zaak dat in Nederland van deze kunstgrepen afstand genomen wordt.

Zowel SSAP 16 als FAS 33 wensen uitdrukkelijk bij de herrekening van resultaten op basis van actuele waarden, handhaving van de belasting last op het- 
zelfde getal als waarmee deze post in de resultatenrekening op basis van his. torische kosten paraisseert. Het IASC laat alle mogelijkheden open. In Nederland ligt dit anders; de Ontwerp aanpassingswet beperkt zich overigens tot de eis dat in de toelichting bij de jaarrekening moet worden aangegeven of, en zo ja hoe, de herwaardering fiscaal wordt verwerkt.

Tenslotte nog de opmerking dat SSAP 16, zowel als FAS 33, voor het loslaten van de vervangingswaarde ten gunste van de opbrengstwaarde de eis formuleren van een geconstateerde van belang zijnde permanente waardedaling onder het niveau van de vervangingswaarde. Meer valt te zeggen ten faveure van de opvatting van het TO (de Ontwerp aanpassingswet laat zich hier niet over uit), dat afwaardering pas plaatsvindt ingeval van discontinuiteit, d.w.z. nadat een beslissing tot beëindiging van een activiteit heeft plaats gehad. Zolang de activiteiten worden voortgezet kan slechts via afschrijving op basis van vervan. gingswaarde inzicht worden gegeven in de uitkomsten van die voortzetting, veelal inzicht in de mate waarin zij verliesgevend blijkt te zijn. 